\title{
Pay attention to the development of local NPO in the education of rural left behind children
}

\author{
Liu Chang \\ College of Humanities and Social Sciences, North China Electric Power University,Beijing 102206
}

13260069647@163.com

Keywords: non-profit organization, student education, rural left behind children.

\begin{abstract}
With the accelerated process of urbanization and industrialization in china, Urban and rural dual structure accelerated the formation and gradually solidified, and the distribution of educational resources in different regions, which causes the left behind children in rural areas to become the object of widespread concern in society, at the same time, also brings a series of social problems. At present, there appeared a large number of NPO based on economic aid and spiritual assistance in every place. The author analyzes the background of the establishment, strategic management and volunteer management.
\end{abstract}

\section{Introduction}

Since 1980s, under the impetus of the globalization of capital and the development of capitalism, the process of urbanization and industrialization in China is accelerating. With the loosening of the urban and rural segmentation system, the youngest and most active labor force in the countryside is allowed to flow into the city. But the rural labor force in the process of migrant workers at the same time is difficult to achieve the overall migration of the family, leaving part of the family members to stay in rural areas, then formed the phenomenon of left behind children in rural areas. The life course of "left behind" is closely related to their growth but their education environment is getting worse. The increasing gap between urban and rural areas, as well as the serious uneven distribution of resources cause it difficult for students to continue to accept higher education, drop out of school and enter society at home, and can cause mental not perfect, even produce to the society of hate, leading to a series of social problems.

In solving the problems of rural left behind children and the education of the family economic difficulties students, it is hard for the government to realize the effective allocation of resources. The sustainable development of urban and rural areas has accelerated the flow of rural labor force,2004-2005 years of official discourse, academic research and media reports, more than 20 million of the amount of time to estimate the number of rural left behind children's group. ${ }^{[1]}$ To 2013, according to the China Women's Federation issued then the rural left behind children, children in rural and urban mobility status report ", China's rural left behind children number has more than 60 million. ${ }^{[2]}$ Visible, the number of rural left behind children so huge and growing speed so fast, in the field of public education demand is too large and the government is unable to intervene, but the government failure can not effectively solve the problem of Education.

Backward rural economic development, and some places are too remote, inconvenient transportation, or there is a serious shortage of water and other issues, leading to a lot of excellent teachers unwilling to go to teach. In recent years, although the countries through a variety of preferential policies, encourage students to teach, or establish the free normal students, still are unable to retain teachers. Due to lack of funds, the children go to school environment is also very difficult, in this kind of obstacle, the market is difficult to achieve the effective allocation of resources.

In this case, with the establishment and development of civil society, the worries about rural education have gradually become the subject of the current academic and social concern, from more and more public figures to college students volunteers, gradually establish a series of non profit organizations to provide material support and spiritual assistance. The personal experience of the Hubei love club Jia Pin, originally a trade union person in charge, part-time network writer, because 
of their unique life experience goes on the road of non-profit organizations. Jiang Yiyan, a public figure, around the teacher's education and get out filming experience, LOVE founded the Jiang Xiaopa Love team, eager to support education for eight years, and in the rural education plays an increasingly important role.

\section{Strategic management of NPO.}

\begin{tabular}{|c|c|c|}
\hline \multirow[b]{2}{*}{$\begin{array}{l}\text { Internal } \\
\text { factors }\end{array}$} & Strength & Weakness \\
\hline & $\begin{array}{l}\text { One,the target to help the } \\
\text { local provinces and cities } \\
\text { in remote areas, the scope } \\
\text { of small, and distance near. } \\
\text { Two,most of the NPO are } \\
\text { equipped with love branch } \\
\text { in the cities, which can } \\
\text { realize the hierarchical } \\
\text { management. }\end{array}$ & $\begin{array}{l}\text { One,part time President of } \\
\text { public officials, personal } \\
\text { ability and time is limited, } \\
\text { and the social influence is } \\
\text { small. } \\
\text { Two,there is not } \\
\text { establishing a sound } \\
\text { management system. }\end{array}$ \\
\hline Opportunities & $\mathrm{SO}$ & SW \\
\hline $\begin{array}{l}\text { One,state of the rural left } \\
\text { behind children and } \\
\text { families of poor students in } \\
\text { poverty related policies to } \\
\text { help. } \\
\text { Two,the gradual formation } \\
\text { of civil society has made } \\
\text { the society pay more } \\
\text { attention to the rural left } \\
\text { behind children and the } \\
\text { poor students in the family } \\
\text { economy. }\end{array}$ & $\begin{array}{l}\text { One, make full use of } \\
\text { national policy, the } \\
\text { implementation of flat } \\
\text { management of Municipal } \\
\text { Bureau of love. } \\
\text { Two,increase publicity } \\
\text { efforts, the operation of a } \\
\text { good network platform, } \\
\text { calling for more attention. }\end{array}$ & $\begin{array}{l}\text { One,recruiting talents, } \\
\text { Strengthening the team, } \\
\text { Establishing a perfect } \\
\text { NPO. } \\
\text { Two, constantly improve } \\
\text { attention, recruit } \\
\text { volunteers, and form a } \\
\text { recycling and continuous } \\
\text { system of volunteers. }\end{array}$ \\
\hline Theats & $\mathrm{ST}$ & WT \\
\hline $\begin{array}{l}\text { One,funding sources } \\
\text { mainly for individual } \\
\text { entrepreneurs to donate, } \\
\text { prone to funding fault, a } \\
\text { shortage of funds. } \\
\text { Two,volunteer have no } \\
\text { formal training, organized } \\
\text { by the parents to } \\
\text { communicate with the } \\
\text { parents of obstacles, and } \\
\text { the children's personal } \\
\text { security issues. }\end{array}$ & $\begin{array}{l}\text { One,establish and maintain } \\
\text { long-term relationships } \\
\text { with entrepreneurs and } \\
\text { increase the relationship } \\
\text { between the funding and } \\
\text { entrepreneurs. } \\
\text { Two,expand other } \\
\text { volunteer activities, such as } \\
\text { charity, material recycling, } \\
\text { to achieve "Self } \\
\text { hematopoiesis". }\end{array}$ & $\begin{array}{l}\text { One,establish links with } \\
\text { local colleges and } \\
\text { universities, and make full } \\
\text { use of the advantages of } \\
\text { College Students' } \\
\text { resources. } \\
\text { Two,activities into the } \\
\text { campus, in the realization } \\
\text { of economic assistance, } \\
\text { while increasing } \\
\text { psychological assistance. }\end{array}$ \\
\hline
\end{tabular}

\section{Human resource management in non profit organizations.}

The rural left behind children as the object of local NPO are voluntary, therefore, the main task of the volunteers for their human resources management have the requirements of specific characteristics.

First of all, the human resource management strategy emphasizes the value system and the role of mission. Such as the Hubei love club and Jiang Xiaopa LOVE team,members of the team is mainly for college students volunteers or fans, Human resource management, therefore, pays more attention to the cultivation of team culture and team culture, and requires the awareness of voluntary service and the enthusiasm of devotion; Emphasizes the combination of human resource management and 
accountability management, in the pursuit of dedication and voluntary at the same time, strengthens the evaluation of performance, so as to enhance the credibility of NPO. The pursuit of professional management, because the president are part-time staff, there are not professional managers, Therefore, strengthening the management of training, or recruitment of professional management personnel, but also ensure that the professional level of staff.

Then, in terms of volunteer management, there is volunteer awareness and public participation awareness. Because of the limitation of time and place, it is difficult to recruit college students. Often is not screening, although the students of higher education institutions, the quality and ability is uneven. There are many deficiencies, but according to reflect most of the management staff, volunteers from colleges and universities in Beijing relatively more responsible, ability is stronger and with volunteer enthusiasm, in activities by the students and accompanying volunteers alike.

Secondly, the quality of voluntary activities depends largely on the quality and ability of the volunteers themselves, mainly relying on personal beliefs, charm and enthusiasm to attract and manage volunteers. The volunteer's hard work is beyond doubt. Because the social influence of local NPO is small, there is often a serious shortage of funds, to receive a variety of forms of donations, volunteer is no work allowance, and ultimately only a volunteer certificate. However, watching students eager eyes and all the joint efforts of all people, a lot of volunteers are adhering to the perseverance.

Finally, the lack of policy support and legal protection. At present, China has not explicitly introduced the non profit organization of the law and the policy support and legal protection is still very lacking, the volunteers and students who have personal safety can only rely on personal insurance. At the same time, in the tax policy, income tax exemption and donation tax breaks and other preferential policies tend to be used by speculators and criminals, leading to problems appeared in the process of implementing the policy, not really the proper implementation of the policy.

From this view, the volunteer has non professional, voluntary, non - return characteristics. In the activities, the quality of the activity depends entirely on the professional level and ability of the volunteers, so volunteer activities face many problems and challenges.

In view of the above analysis, the author put forward the following suggestions:

One,there is going to be sufficient funds to protect, and establish with entrepreneurs maintain long-term relations of funding, increase contact between recipients of aid and entrepreneur, make full use of network resources, or organize charity activities, raise funds, and create a good environment for volunteers and recipients, the perfect plan.

Two,seeking to hire talented people, NPO in salary is not high, and not easy to recruit the best talent, so NPO should pay great attention to the talents, and contact with major colleges to make full use of the resource advantages of college students, provide adequate working conditions.

Three,the rational use of talent, energy level matching, adhere to the applicable principle of management, improveing the degree of specialization of team members, strengthening train and improving the professional requirements.

Four,continuous development of talent, so that the development and use of both, to meet the development goals of non-profit organizations, but also to try to meet the needs of individual growth and development of employees.

Five,retain the outstanding talent, through the non-profit organization's unique informal and characteristics of the team cultural characteristics, maintaining the work of the outstanding staff of the long-term.

\section{Literature References}

[1].Ye Jingzhong, Pan Lu. Review of research on rural left behind children [J]. Journal of China Agricultural University (SOCIAL SCIENCE EDITION), 2009 (2):5-17 .

[2].Chinese Federation news: " Urban children and rural migration study the situation of children left behind in rural China (Full text)". 
[3].Zhang Ran, Marie diss Newman. Emotional labor management: NPO human resource management perspective [J]. Zhejiang University Journal (HUMANITIES AND SOCIAL SCIENCES EDITION), 2012,02:5-21.

[4].Wang Xiangnan. Institutional design for the development of China's NPO [D]. Northeast Normal University, 2014. 